\title{
From Belgium
}

\author{
Jan Dequeker
}

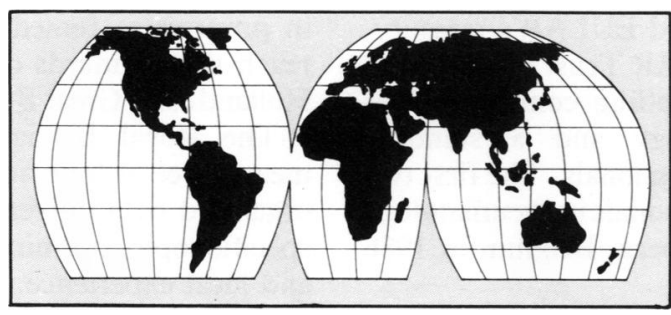

Belgium is a small densely populated (10 million) country on the west of the continent-the British would say 'squeezed between large countries'. No wonder it has been Europe's battle field for centuries. Despite this, rheumatology in Belgium is thriving. Belgium is also a trilingual country: Flemish (which is the same as Dutch), French, and German. This diversity of languages and cultural backgrounds is its strength and holds promise for Europe 1992. Our position between the northern European Anglo-Saxon world, the southern Latin world, and the eastern German world confers on us special characteristics, and results in industriousness, reliability, and enjoyment of leisure.

The Royal Belgian Rheumatology Society is the second oldest in the world and celebrated its 50th anniversary in 1976. Belgian rheumatology has not remained fixed in spa treatments (incidently Spa is a. Belgian resort). As in many other parts of the world Belgian rheumatology has moved from a specialty aiming at symptomatic relief by physical therapy to patients with undifferentiated diagnosis to a diagnostic discipline akin to internal medicine with an expertise in musculoskeletal and connective tissue diseases in all their aspects: clinical, immunological, endocrinological as well as imaging, treatment, and rehabilitation. Rheumatology teaching units are found in all university hospitals. Formal training in rheumatology comprises a three year (sometimes four) rotation in internal medicine and two years (sometimes three) in full time rheumatology.

Despite the official uniformity, rheumatology practice varies from university to university according to the personality and background of the chairman or department. In some units there is greater emphasis on immunology, in others on physical medicine and rehabilitation, or on metabolic bone diseases-the last an interest held in common with French rheumatology. In general, all units offer a comprehensive service to the patients.

The university units all have active clinical and research activities which have become known world wide: Professor E Veys's group (University Ghent) with Dr H Mielants, Dr G Verbruggen, and Dr F De Keyser for the relation between gut inflammation and arthritis, immunotherapy of rheumatoid arthritis (cytokines (interferon $\gamma$ ) and cytokine inhibitors), influence of cytokines on growth factors and chondrocyte cultures, and detection and characterisation of antinuclear antibodies; Professor P Franchimont's group (University Liège) with Dr J Y Reginster, Dr P F Zangerle, and Dr M Malaise for basic endocrinological, cellular, and biochemical immunology, bone and cartilage research associated with a clinic activity in prevention and treatment of osteoporosis and osteoarthritis; Professor Ch Nagant de Deuxchaisnes's group (Louvain University in Brussels) with Dr J P Devogelaer, $\mathrm{Dr}$ D Manicourt, and Dr F Houssiau for physiopathological aspects and invasive and noninvasive measurements of metabolic bone diseases, osteoporosis, osteomalacia, Paget's disease, basic and clinical research in cartilage and in connective tissue diseases; Professor J P Famaey with Dr A Peretz for the pharmacology of non-steroidal anti-inflammatory drugs and trace elements on rheumatic diseases; Professor T Appelboom with Dr J P Hauzeur for immunorheumatology and the history of rheumatic diseases (University of Brussels, ULB); Professor $S$ Orloff's group (University of Brussels, VUB) with Dr A Huybrechts and Dr L Verbruggen for diagnostic arthroscopy, research on aseptic bone necrosis, collagen and bone metabolism, measurement of pain and inflammation; Professor J Dequeker's group (Leuven) with Dr P Geusens, Dr M Walravens, Dr R Westhovens, and Dr B Grillet for noninvasive bone mass measurements, noncollagenous proteins of bone and growth factors, treatment of established osteoporosis, the inverse relation between osteoarthritis and osteoporosis, antinuclear antibody research, allied health professionals and teamwork in rheumatology; and Dr L Declerck's group, who recently started at the University of Antwerp, for immune complexes containing IgE.

As in many other countries the Royal Belgian Rheumatology Society had its journal, Acta Rheumatologica Belgica. To be heard, read, and quoted in the scientific world, however, the use of the Esperanto scientifica 'English' became a must. Therefore it was decided 10 years ago to convert Acta Rheumatolgica Belgica into a journal with an international editorial board of distinguished referees, and the journal was renamed Clinical Rheumatology. As the editor of the journal I was privileged to see its growth over the years with contributions from all over the world: editorials, reviews, original articles, case reports, letters, and abstracts of important meetings in Europe. The green journal with its Leonardo da Vinci like emblem was the first journal to include referees from eastern European
Weligerveld 1, 3212 Lubbeek (Pellenberg) Belgium $\mathrm{J}$ Dequeker 
countries on its editorial board-anticipating a wider Europe. The journal hopes to remain a key publication for all those in rheumatological practice interested in updating their knowledge in clinical aspects and clinical rheumatology research.

Representatives of the Belgian Rheumatology Society have been active in ILAR and EULAR executive committees and standing committees. Strong support has been given towards improving ILAR's secretariat and EULAR's treasury, towards creating an EULAR Trust Foundation, and towards starting standing committees for investigative rheumatology and a standing committee for allied professionals. The first two meetings for allied professionals in rheumatology were organised in Pellenberg, Belgium in 1986 and 1988.

All is not 'rozegeur en maneschijn' (moonlight and roses) in Belgian rheumatology. We have a problem with a number of doctors, trained in physical therapy and rehabilitation, in internal medicine, or in immunology, who claim to be knowledgeable about rheumatology. This confuses the public and lowers standards of patients' management by concentrating on one sided issues. Such doctors often take up positions in hospitals that would be better filled by professionally trained rheumatologists.

The second field in which rheumatology in Belgium falls behind practice in some neighbouring countries is in the lack of a well run, effective Arthritis Foundation aiming at patient and public education, at financing rheumatology research, and at obtaining more support from authorities for rheumatic patients. Serious efforts in collaboration with the social league are in progress to remedy this, and it is hoped to reach the standards of Scandinavian countries, Holland, and Great Britain in the near future.

The Royal Belgian Rheumatology Society meets three or four times a year. One meeting is organised by a university unit and deals with a specific topic, combining international expertise and local experience. Another is organised at a peripheral centre, alternately in the north and south of the country, and the third is a business meeting with free communications, held in Brussels at the end of the year. A previous tradition of joint meetings with rheumatology societies of neighbouring countries was revived in 1989 in Lille, and a meeting in Spa with the Dutch Rheumatology Society was held earlier this year. 